\title{
KESIAPAN PSIKOLOGIS IBU HAMIL TRIMESTER III DALAM PERSIAPAN PERSALINAN PASCA RELAKSASI HYPNOBIRTHING
}

\author{
Henik Istikhomah, Dyah Ayu Putri Mumpuni \\ Kementerian Kesehatan Politeknik Kesehatan Surakarta Jurusan Kebidanan
}

\begin{abstract}
Psychological Readiness Pregnancy Trimester III, Post-Relaxation Hypnobirthing. A number of fear seen in pregnant women during the third trimester. Unpreparedness to face the birth mother to be one of the causes of high maternal mortality rate. Mother began to feel fear of pain and the physical dangers that will arise at the time of delivery. Because they were, the mother must make themselves maintain the harmony of mind and body through relaxation. Hypnobirthing techniques can help relax the muscles so that mothers avoid the anxiety and may help mothers more calm in the face of labor. The purpose of this study to describe the psychological readiness of third trimester pregnant women in childbirth after relaxation hypnobirthing. Quantitative descriptive research. The population in this study is the third trimester pregnant women who have followed the relaxation hypnobirthing $\geq 4$ times in BPM and BPM Yessi Yosi Trihana Aprilia Klaten. Saturated sampling technique is sampling as many as 30 third trimester pregnant women who had attended relaxation hypnobirthing $\geq 4$ times as respondents. Of the 30 respondents third trimester pregnant women who attended $\geq 4$ times showed 19 respondents (63.30\%) declared ready psychologically to face childbirth after following the relaxation of hypnobirthing $\geq 4$ times. And 11 respondents (36.70\%) are not ready psychologically to face the post-relaxation hypnobirthing childbirth $\geq 4$ times. Most of the third trimester pregnant women are better prepared psychologically to face childbirth after following the relaxation of hypnobirthing $\geq 4$ times in BPM and BPM Yessi Yosi Trihana Aprilia Klaten.
\end{abstract}

Keywords: Psychological Readiness Pregnancy Trimester III, Post-Relaxation Hypnobirthing.

\begin{abstract}
Abstrak: Kesiapan Psikologis Ibu Hamil Trimester III, Pasca Relaksasi Hypnobirthing. Sejumlah ketakutan terlihat pada ibu hamil selama trimester ketiga. Ketidaksiapan ibu menghadapi persalinan menjadi salah satu penyebab tingginya AKI. Ibu mulai merasa takut akan rasa sakit dan bahaya fisik yang akan timbul pada waktu melahirkan. Kerena itu, ibu harus menyempatkan diri memelihara keselarasan pikiran dan tubuh lewat relaksasi. Teknik hypnobirthing dapat membantu merilekskan otot-otot sehingga ibu terhindar dari kecemasan dan dapat membantu ibu lebih tenang dalam menghadapi persalinan. Tujuan penelitian ini untuk mengetahui gambaran kesiapan psikologis ibu hamil trimester III dalam persiapan persalinan pasca relaksasi hypnobirthing. Jenis penelitian deskriptif kuantitatif. Populasi dalam penelitian ini adalah ibu hamil trimester III yang sudah mengikuti relaksasi hypnobirthing $\geq 4$ kali di BPM Yosi Trihana dan BPM Yessi Aprillia Klaten. Teknik sampling adalah sampling jenuh yaitu sebanyak $30 \mathrm{ibu}$ hamil trimester III yang pernah mengikuti relaksasi hypnobirthing $\geq 4$ kali sebagai
\end{abstract}


responden. Dari 30 responden ibu hamil trimester III yang pernah mengikuti $\geq 4$ kali didapatkan hasil 19 responden $(63,30 \%)$ dinyatakan siap psikologisnya dalam menghadapi persalinan setelah mengikuti relaksasi hypnobirthing $\geq 4$ kali. Dan 11 responden $(36,70 \%)$ tidak siap psikologisnya dalam menghadapi persalinan pasca relaksasi hypnobirthing $\geq 4$ kali. Sebagian besar ibu hamil trimester III lebih siap secara psikologis dalam menghadapi persalinannya setelah mengikuti relaksasi hypnobirthing $\geq 4$ kali di BPM Yosi Trihana dan BPM Yessi Aprillia Klaten.

Kata Kunci: Kesiapan Psikologis Ibu Hamil Trimester III, Pasca Relaksasi Hypnobirthing.

\section{PENDAHULUAN}

Menurut data Survei Demografi Kesehatan Indonesia (SDKI) pada tahun 2011, Angka Kematian Ibu 228/100.000 kelahiran hidup dan terakhir pada tahun 2012 angka itu naik menjadi 359/100.000 kelahiran hidup. Angka Kematian Ibu mulai menjadi sorotan terkait sulitnya mencapai target MDGs (Millennium Development Goals) yang tinggal 2 Tahun lagi yaitu menurunkan Angka Kematian Ibu menjadi 102/100.000 kelahiran hidup pada tahun 2015, untuk menurunkan Angka Kematian Ibu diperlukan upaya-upaya yang terkait dengan kehamilan, kelahiran dan nifas (WHO, 2011). Menurut Dinas Kesehatan Provinsi Jawa Tengah pada tahun 2012 AKI di Jawa Tengah meningkat menjadi 116,34/100.00 KH.

Pelayanan antenatal merupakan pilar kedua didalam Safe Motherhood yang merupakan sarana agar ibu lebih siap menghadapi persalinan. Ketidaksiapan ibu menghadapi persalinan menjadi salah satu penyebab tingginya AKI. Persiapan persalinan meliputi persiapan psikologi, persiapan fisik, persiapan dana, dan rencana persalinan yang meliputi rencana tempat persalinan, memilih tenaga kesesahatan, pendamping saat persalinan, pembuat keputusan, transport, dan calon donor.
(Depkes RI, 2002 dalam Rahmaningrum, 2012).

Selama kehamilan kebanyakan wanita mengalami perubahan psikologis dan emosional. Perubahan fisik dan emosional yang kompleks, memerlukan adaptasi terhadap penyesuaian pola hidup dengan proses kehamilan yang terjadi (Mansur, 2009: 134). Menurut hasil penelitian Astria (2009) sejak saat hamil, ibu sudah mengalami kecemasan. Kecemasan meningkat menjelang persalinan terutama pada trimester III. Pada ibu hamil trimester III umumnya mengalami kecemasan dalam menghadapi persalinan $(52.5 \%)$ dan sisanya tidak mengalami kecemasan $(47.5 \%)$.

Sejumlah ketakutan terlihat selama trimester ketiga. Wanita mungkin khawatir terhadap hidupnya dan bayinya, dia tidak akan tahu kapan dia melahirkan. Ibu mulai merasa takut akan rasa sakit dan bahaya fisik yang akan timbul pada waktu melahirkan. Ibu memerlukan dukungan dari suami, keluarga dan bidan (Kusmiyati, 2008: 73).

Saat hamil kondisi hormon cenderung menciptakan ketidakstabilan tubuh dan pikiran sehingga ibu menjadi lebih mudah panik, mudah tersinggung, jauh lebih sensitif, mudah terpengaruh, cepat marah, menjadi tidak rasional, dan sebagainya. Kerena itu, ibu harus 
menyempatkan diri memelihara keselarasan pikiran dan tubuh lewat relaksasi (Ilmiasih, 2009).

Relaksasi untuk persalinan saat ini telah dikenal luas dengan nama Hypnobrirthing. Teknik relaksasi semacam ini sangat bermanfaat untuk mengurangi rasa sakit dan tekanan emosi selama persalinan, tanpa perlu menggunakan obat bius (Andriana, 2007: 31). Hypnobirthing adalah metode yang dilakukan oleh ibu yang mengandung dan yang akan melahirkan, dengan bantuan tenaga medis untuk menghilangkan rasa takut, panik, tegang, dan tekanan-tekanan lain yang menghantui ibu saat akan melahirkan. Stres yang berkepanjangan pada ibu yang mengandung akan mempengaruhi kehamilan dan mempersulit proses melahirkan maka dengan melakukan latihan Hypnobirthing diharapkan mampu mengurangi stres dan membantu proses persalinan menjadi lancar (Dwi, 2010).

Teknik hypnobirthing dapat membantu merilekskan otot-otot sehingga ibu terhindar dari kecemasan dan dapat membantu ibu lebih tenang dalam menghadapi persalinan. Teknik hypnobirthing merupakan salah satu cara yang dapat di aplikasikan oleh ibu hamil untuk memperoleh ketenangan saat menghadapi kehamilan dan persalinan (Ilmiasih, 2010).

Berdasarkan hasil penelitian Ilmiasih (2010) menunjukkan Tingkat kecemasan ibu hamil sebelum dilaksanakan latihan relaksasi hypnobirthing $63 \%$ tingkat kecemasan ringan dan $12 \%$ mengalami cemas, sedangkan hasil prosentase kecemasan ibu hamil sesudah dilakukan latihan relaksasi hipnobirthing adalah 56\% tidak cemas dan $38 \%$ tingkat kecemasan ringan. Hal ini menunjukkan penurunan tingkat kecemasan pada ibu hamil setelah dilakukan latihan relaksasi hypnobirthing.

Berdasarkan studi pendahuluan yang peneliti lakukan di BPM Yosi
Trihana dan BPM Yessi Aprillia pada tanggal 13 Maret 2014 di peroleh data jumlah ibu hamil trimester ketiga yang pernah mengikuti relaksasi hypnobirthing menimal 4 kali sebanyak 30 ibu hamil, dan dari wawancara yang peneliti lakukan di peroleh data dari jumlah 10 ibu hamil, ada 8 ibu yang mengatakan setelah relaksasi hypnobirthing ibu merasa lebih nyaman dalam menjalani kehamilannya, rileks, dan lebih tenang dalam menghadapi persalinan setelah mengikuti relaksasi hypnobirthing.

Dari latar belakang dan studi pendahuluan yang peneliti lakukan penulis tertarik untuk mengetahui "Gambaran kesiapan psikologis ibu hamil trimester III dalam persiapan persalinan pasca relaksasi hypnobirthing di BPM Yosi Trihana dan BPM Yessi Aprillia Klaten".

\section{METODE PENELITIAN}

Penelitian ini merupakan jenis penelitian deskriptif. Populasi dalam penelitian ini adalah ibu hamil trimester III yang pernah mengikuti relaksasi hypnobirthing minimal 4 kali sampai bulan april tahun 2014 di BPM Yosi Trihana dan BPM Yessi Aprillia Klaten terdapat 30 ibu hamil. Teknik Pengambilan sampel dengan teknik sampel jenuh.

\section{HASIL PENELITIAN}

1. Karakteristik responden

a. Umur

Tabel 1

Distribusi frekuensi umur ibu hamil trimester III di BPM Yossi Trihana dan BPM Yessi Aprillia Klaten

\begin{tabular}{llll}
\hline No & Umur & Jumlah & $\begin{array}{l}\text { Prosentase } \\
(\%)\end{array}$ \\
\hline 1 & $<20$ tahun & 3 & 10,00 \\
2 & 20-35 tahun & 23 & 76,70 \\
3 & $>35$ tahun & 4 & 13,30 \\
\hline & Jumlah & 30 & 100,00
\end{tabular}

Sumber : Data Primer 2014

b. Pendidikan 


\section{Tabel 2}

Distribusi frekuensi pendidikan ibu hamil trimester III di BPM Yossi Trihana dan BPM Yessi Aprillia

Klaten.

\begin{tabular}{llll}
\hline No & Pendidikan & Jumlah & $\begin{array}{l}\text { Prosenta } \\
\text { se }(\%)\end{array}$ \\
\hline 1 & Tamat SD & 3 & 10,00 \\
2 & Tamat & 8 & 26,70 \\
3 & SLTP & 8 & 26,70 \\
4 & Tamat & 11 & 36,60 \\
& SLTA & & \\
& Perguruan & \\
& tinggi & & 100,00 \\
\hline & Jumlah & 30 & \\
\hline c. & Pekerjaan &
\end{tabular}

Tabel 3

Distribusi frekuensi pekerjaan ibu hamil trimester III di BPM Yossi Trihana dan BPM Yessi Aprillia Klaten.

\begin{tabular}{llll}
\hline No. & Pekerjaan & Jumlah & Prosentas \\
\hline 1. & Bekerja & 17 & 56,70 \\
2. & Tidak bekerja & 13 & 43,30 \\
\hline \multicolumn{2}{l}{ Jumlah } & 30 & 100,00 \\
\hline
\end{tabular}

Sumber : Data Primer 2014

d. Graviditas

Tabel 4

Distribusi frekuensi pendidikan ibu hamil trimester III di BPM Yossi Trihana dan BPM Yessi Aprillia Klaten

\begin{tabular}{llll}
\hline No. & Graviditas & Jumlah & $\begin{array}{l}\text { Prosentase } \\
(\%)\end{array}$ \\
\hline 1. & Primigravida & 15 & 50,00 \\
2. & Multigravida & 15 & 50,00 \\
\hline Jumlah & 30 & 100,00 \\
\hline
\end{tabular}

Sumber : Data Primer 2014

e. Kesiapan Psikologis ibu dalam menghadapi persalinan

Tabel 5

Distribusi frekuensi kesiapan psikologis ibu hamil trimester III dalam persiapan persalinan pasca relaksasi hypnobirthing di BPM Yosi

Trihana dan BPM Yessi Aprillia Klaten

No. Kesiapan Jumlah Prosentase (\%)

\begin{tabular}{llll}
\hline 1. & Siap & 19 & 63,30 \\
\hline 2. & Tidak siap & 11 & 36,70 \\
\hline Jumlah & 30 & 100,00 \\
\hline
\end{tabular}

\section{PEMBAHASAN}

Dari hasil penelitian dapat dilihat bahwa mayoritas umur ibu hamil trimester III dalam persiapan persalinan pasca mengikuti relaksasi hypnobirthing di BPM Yossi Trihana dan BPM Yessi Aprillia Klaten adalah umur 20-35 tahun sebanyak 23 responden $(76,70 \%)$. Hal ini sesuai dengan teori menurut Hartanto (2002), yang menyatakan bahwa umur $20-35$ tahun merupakan umur reproduksi sehat dan paling baik untuk mengandung dan melahirkan. Keadaan ini juga didukung dengan teori yang dikatakan Dedeh dalam penelitian Astria (2009), bahwa karakteristik pada ibu hamil berdasarkan umur sangat berpengaruh terhadap perhatian dalam proses persalinan, dimana semakin muda umur ibu maka semakin kurang perhatian serta pengalaman yang dimiliki ibu hamil karena ketidaksiapan ibu dalam menerima sebuah kehamilan, selain itu usia yang masih muda sistim reproduksi yang belum matang, sehingga akan berisiko terjadi gangguan selama kehamilan. Hal ini akan berdampak pada persiapan persalinan yang minim dan dapat berdampak buruk selama proses persalinan berlangsung.

Hasil penelitian menunjukkan bahwa mayoritas pendidikan ibu hamil trimester III dalam persiapan persalinan pasca mengikuti relaksasi hypnobirthing di BPM Yosi Trihana dan BPM Yessi Aprillia Klaten adalah perguruan tinggi sebanyak 11 responden $(36,60 \%)$, ini menunjukkan bahwa masih banyak ibu hamil yang mempunyai tingkat pendidikan tinggi dalam mempersiapkan persalinannya. Hal ini sesuai dengan teori yang dikatakan Kodyat dalam penelitian Astria (2009), bahwa Tingkat pendidikan turut menentukan mudah tidaknya seseorang 
menyerap dan memahami pengetahuan tentang persiapan menghadapi persalinan yang mereka peroleh dan Tingkat pendidikan turut menentukan rendah tidaknya seseorang menyerap dan memakai pengetahuan.

Berdasarkan pekerjaan hasil penelitian menunjukkan bahwa mayoritas ibu hamil trimester III dalam persiapan persalinan pasca relaksasi hypnobirthing di BPM Yosi Trihana dan BPM Yessi Aprillia Klaten adalah bekerja sebanyak 17 responden $(56,70 \%)$, ini menunjukkan ibu hamil yang bekerja dapat dengan mudah memperoleh informasi mengenai persiapan menjelang persalinan. Hal ini sesuai dengan teori yang dikatakan Astria (2009), bahwa pekerjaan ibu hamil tidak hanya menunjukkan tingkat sosial ekonomi, melainkan juga menunjukkan ada tidaknya interaksi ibu hamil dalam masyarakat yang luas dan keaktifan pada organisasi tertentu, dengan asumsi ibu yang bekerja akan memiliki pengetahuan yang lebih tinggi dan menerima informasi lebih cepat daripada ibu yang tidak bekerja.

Berdasarkan graviditas hasil penelitian ditemukan terdapat ibu hamil primigravida dan multigravida memiliki jumlah yang sama yaitu masing-masing 15 responden $(50,00 \%)$, dimana graviditas dapat mempengaruhi kesiapan ibu dalam menghadapi persalinannya. Keadaan ini sesuai dengan teori yang dikatakan Kartono dalam penelitian Astria (2009), bahwa Bagi primigravida, kehamilan yang dialaminya merupakan pengalaman pertama kali, sehingga trimester III dirasakan semakin mencemaskan karena semakin dekat dengan proses persalinan. Ibu akan cenderung merasa cemas dengan kehamilannya, merasa gelisah, dan takut menghadapi persalinan, mengingat ketidaktahuan menjadi faktor penunjang terjadinya kecemasan. Sedangkan ibu yang pernah hamil sebelumnya (multigravida), mungkin kecemasan berhubungan dengan pengalaman masa lalu yang pernah dialaminya.

Ibu hamil khususnya pada trimester ketiga pada saat menjelang proses kelahiran, seorang wanita akan mengalami perasaan yang bercampur baur. Perasaan bahagia penuh harapan diiringi gelisah, takut dan ngeri pada proses persalinan. Dalam hal ini psikologis ibu hamil trimester ketiga yang siap dalam menghadapi persalinan pasca relaksasi hypnobirthing di BPM Yossi Trihana dan BPM Yessi Aprillia Klaten terdapat 19 responden $(63,30 \%)$ ini menunjukkan ibu lebih tenang dan tidak takut dalam mengahadapi persalinannya setelah mengikuti relaksasi hypnobirthing. Hal ini sesuai dengan teori kusmiyati, et al (2008) yang mengatakan bahwa peristiwa kehamilan merupakan suatu rentang waktu, dimana tidak hanya terjadi perubahan fisiologis, tetapi juga terjadi perubahan psikologis yang memerlukan penyesuaian emosi, pola berfikir, dan prilaku yang berlanjut hingga bayi lahir.

Keadaan tersebut juga sesuai dengan teori yang dinyatakan Batbual (2010), mengatakan bahwa Hypnobirthing merupakan salah satu alternatif bagi bidan atau petugas kesehatan untuk membantu ibu agar mampu beradaptasi terhadap perubahan psikologis yang dialami selama masa kehamilan. Berbagai penelitian telah membuktikan bahwa metode hypnobirthing sangat efektif mengatasi kecemasan ibu selama kehamilan dan membantu menyiapkan mental ibu untuk memasuki persalinan dengan lancar dan nyaman. Ibu dapat dilatih untuk melakukan self hypnosis, dengan memberikan sugesti-sugesti positif serta berkomunikasi dengan janin didalam kandungan.

Dalam hal ini masih terdapat ibu hamil trimester ketiga yang tidak siap dalam menghadapi persalinannya pasca relaksasi hypnobirthing yaitu sejumlah 11 responden $(36,70 \%)$ ini menunjukkan bahwa ibu masih takut 
dalam menghadapi persalinannya karena memungkinkan ini terjadi karena ibu tidak dapat berlatih relaksasi dirumah dan memiliki kesulitan dalam mengikuti tehnik self hypnosis dalam relaksasi hypnobirthing, sehingga ibu tidak dapat rileks dan berimajinasi dalam mengikuti relaksasi hypnobirthing dan pikiran alam bawah sadar ibu tidak dapat menerima sugestisugesti yang diberikan kepada ibu saat relaksasi hypnobirthing. Hal ini sesuai dengan teori menurut Batbual (2010), hypnosis diri (self-hypnosis) dan penanaman sugesti adalah prinsip dasar hypnobirthing, yang digunakan sebagai latihan selama masa kehamilan. Latihan hypnosis ini dapat dilakukan minimal 4x selama masa kehamilan, dan akan lebih efektif bila ibu melatih sendiri dirumah atau self hypnosis, agar sugesti positif dapat terekam dibawah sadar dan menjadi nyata dalam proses persalinan.

Hal ini juga di perkuat dengan teori yang dikatakan Andriana (2007), bahwa apabila kita rajin berlatih relaksasi, makin lama kita akan terbiasa dan mudah untuk memulai latihan. Jika awalnya sulit untuk memasuki kondisi rileks, setelah beberapa kali latihan kita akan dapat merasakan bedanya. Karena itu, jangan berhenti berusaha karena makin kita terbiasa dengan kondisi rileks, makin mudah kita mencapai kondisi tersebut, sekalipun kita sedang berada dalam situasi genting

\section{DAFTAR RUJUKAN}

Andriana, E. 2007. Melahirkan tanpa rasa sakit dengan metode hypnobirthing. PT. Bhuana Ilmu Populer. Jakarta.

Astria, Y. 2009. Hubungan Karakteristik Ibu Hamil Trimester III Dengan Kecemasan Dalam Menghadapi Persalinan Di Poliklinik Kebidanan Dan Kandungan Rsup Fatmawati Tahun 2009. Skripsi. Program Studi Ilmu
Keperawatan

Fakultas

Kedokteran Dan Ilmu Kesehatan Universitas Islam Negeri Syarif Hidayatullah. Jakarta.

Batbual, B. 2010. Hypnosis Hypnobirthing nyeri persalinan dan berbagai metode penanganannya. Gosyen Publishing. Yogyakarta.

Dinas Kesehatan Jawa Tengah. 2012. Profil Kesehatan Jawa Tengah Tahun 2012. Retrieved from http://www.dinkesjateng.org.

Dwi, M. 2010. Stres Pada Saat Akan Melahirkan Antara Ibu Yang Melakukan Hypnobirthing Dan Yang Tidak Melakukan Hypnobirthing. Tesis. Fakultas psikologi Unika Soegijapranata.

Hidayat, A.A. 2011. Metodologi Penelitian Kebidanan dan Teknik Analisis Data. Cetakan ke empat. Salemba Medika. Jakarta.

Ilmiasih, R. 2010 Pengaruh Teknik Hypnobirthing Terhadap Tingkat Kecemasan Ibu Hamil Pada Masa Persiapan Menghadapi Persalinan. Disertai. Fakultas Ilmu Kesehatan Jurusan Keperawatan Universitas Muhammadiyah. Malang.

Kusmiyati et al., 2008. Perawatan ibu hamil. Fitramaya. Yogyakarta.

Mansur, H. 2009. Psikologi Ibu Dan Anak Untuk Kebidanan. Salemba Medika. Jakarta.

Rahmaningrum, F. 2012. Tingkat Pengetahuan Ibu Primigravida Trimester III Tentang Persiapan Persalinan. Kti. Program Studi Diploma III Kebidanan Sekolah Tinggi Ilmu Kesehatan Kusuma Husada. Surakarta. 